\title{
CARACTERIZAÇÃO FÍSICA E FÍSICO-QUÍMICA DE RIZOMAS E AMIDO DO LÍRIO-DO-BREJO (Hedychium coronarium) ${ }^{1}$
}

\author{
Diego Palmiro Ramirez Ascheri², Wellington de Souza Moura², \\ José Luis Ramírez Ascheri ${ }^{3}$, Carlos Wanderlei Piler de Carvalho ${ }^{3}$
}

\section{ABSTRACT \\ PHYSICAL AND PHYSICOCHEMICAL \\ CHARACTERIZATION OF Hedychium coronarium RHIZOMES AND STARCH}

The objectives of this research were to evaluate the chemical composition of Hedychium coronarium rhizomes and isolate and characterize their starch by conducting physical and physicochemical analyses. The chemical composition of isolated starch granules was also determined, as well as shape, size, particle distribution size by laser diffraction, paste viscosity by rapid visco-analysis, swelling power, water solubility index, thermal property by differential scanning calorimetry, and crystallinity by X-ray diffraction. Rhizomes presented high water content and low lipids, carbohydrates, ash, protein and fiber levels. Due to its low dry matter content (17.3\%), with $21.97 \%$ of starch, as well as long fibers and latex, which hamper starch extraction, the white ginger lily rhizomes are not interesting as a starch source. The isolated starch showed $99.2 \%$ purity, with $37.2 \%$ of amylase content. The starch granules presented an irregular polyhedral shape and average size of $38.2 \mu \mathrm{m}$. The crystalline structure of the starch granules was type A, which is maintained by strong internal associative forces that reduce water solubility. The starch gelatinization temperature occurs between $73.1^{\circ} \mathrm{C}$ and $78.7^{\circ} \mathrm{C}$. The starch paste viscosity profile showed high stability at $95^{\circ} \mathrm{C}$ and high tendency to retrograde, suggesting its use in adhesive and food industries.

KEY-WORDS: Hedychium coronarium; physicochemical and functional properties; paste viscosity; starch thermal property.

\section{INTRODUÇÃO}

O amido é encontrado em grande concentração na natureza, principalmente em grãos de cereais, tubérculos, raízes e leguminosas (Leonel \& Cereda 2002). Por seu uso peculiar, indústrias de alimentos estão interessadas na identificação e no desenvolvi-

\section{RESUMO}

O presente trabalho teve por objetivos avaliar a composição de rizomas do lírio-do-bejo (Hedychium coronarium) e isolar e caracterizar seu amido, por meio de análises físicas e físico-químicas. A composição química dos grânulos de amido isolados dos rizomas também foi determinada, bem como o formato, tamanho, distribuição de tamanho de partícula por difração a laser, viscosidade de pasta em analisador rápido de viscosidade, poder de inchamento, índice de solubilidade em água, propriedade térmica por calorimetria diferencial de varredura e cristalinidade por difração de raios X. Observouse que os rizomas apresentaram elevado teor de água e baixos teores de matéria graxa, carboidratos, cinzas, proteínas e fibras. Os rizomas de lírio-do-brejo apresentam-se inadequados para produção de amido, devido ao baixo teor de matéria seca (17,3\%), com $21,97 \%$ de amido, bem como fibras longas e látex, que dificultam a extração do amido. $\mathrm{O}$ amido extraído apresentou pureza de 99,2\%, com 37,2\% de amilose. Os grânulos de amido apresentaram forma poliédrica irregular e tamanho médio de $38,2 \mu \mathrm{m}$. Constatou-se que a estrutura cristalina dos grânulos de amido é do tipo A, a qual é mantida por intensas forças associativas internas, que reduzem sua solubilidade em água. A temperatura de gelatinização do amido ocorre entre $73,1^{\circ} \mathrm{C}$ e $78,7^{\circ} \mathrm{C}$. O perfil de viscosidade de pasta do amido mostrou alta estabilidade a $95^{\circ} \mathrm{C}$ e grande tendência à retrogradação, sendo indicado para uso em indústria de adesivos e alimentos.

PALAVRAS-CHAVE: Hedychium coronarium; propriedades físicas, físico-químicas e funcionais; viscosidade de pasta; propriedade térmica do amido.

mento de espécies que produzam amidos nativos, com características físico-químicas e funcionais especiais, para manter e/ou realçar as propriedades dos seus produtos, mesmo após estocagem e refrigeração (Bobbio \& Bobio 2003). Esta macromolécula pode, entre outras funções, facilitar o processamento, conferir textura, servir como espessante, fornecer

1. Trabalho recebido em fev./2009 e aceito para publicação em jun./2010 (nº registro: PAT 5570/ DOI: 10.5216/pat.v40i2.5570).

2. Universidade Estadual de Goiás, Unidade Universitária de Ciências Exatas e Tecnológicas, Curso de Mestrado em Ciências Moleculares, Anápolis, GO, Brasil.E-mails: ascheridpr@gmail.com, bussund@ig.com.br.

3. Empresa Brasileira de Pesquisa Agropecuária, Embrapa Agroindústria de Alimentos, Setor de Tecnologia de Extrusão de Alimentos, Guaratiba, RJ, Brasil.E-mails: ascheri@ctaa.embrapa.br, carlos.piler@gmail.com. 
sólidos em suspensão e proteger os alimentos durante o processamento.

As propriedades físico-químicas e funcionais dos amidos nativos das diferentes espécies vegetais são influenciadas por suas estruturas granular e molecular (Wang \& White 1994a). As propriedades mais importantes para a utilização do amido, na elaboração de alimentos e outras aplicações industriais, incluem as físico-químicas - gelatinização e retrogradação - e as funcionais: solubilidade, inchamento, absorção em água, sinerese e comportamento reológico de suas pastas e géis moleculares (Wang \& White 1994b).

Hernández-Medina et al. (2008) destacam que, durante o processo de gelatinização, a ordem molecular dentro dos grânulos do amido é destruída gradual e irreversivelmente. Por isto, a temperatura de gelatinização é característica para cada tipo de amido e depende, fundamentalmente, da transição vítrea da fração amorfa do amido. Alguns fenômenos ocorrem durante o processo: a ordem molecular e, portanto, a birrefringência, se perde e os grânulos perdem sua cristalinidade, absorvem grande quantidade de água, provocam o inchamento e tem seu volume aumentado. Algumas moléculas são solubilizadas, particularmente a amilose, que se difunde no meio aquoso e, com o aquecimento continuado, é quebrada, observando-se solubilização parcial. A pasta de amido obtida depois da gelatinização não é estável, já que, durante o armazenamento, ocorrem transformações estruturais que, em conjunto, recebem o nome de retrogradação.

Existem, na natureza, diversas espécies vegetais fontes de amido, cujas propriedades ainda não foram elucidadas, como é o caso do lírio-dobrejo (Hedychium coronarium). Esta planta apresenta ampla utilização, principalmente farmacológica e ornamental (Agarez et al. 1994). Dessa forma, este trabalho teve por objetivos contribuir com o estudo do rizoma do lírio-do-brejo, bem como isolar e caracterizar seu amido, por meio de análises físicas e físico-químicas.

\section{MATERIAL E MÉTODOS}

Os rizomas do lírio-do-brejo foram obtidos de plantas sadias das margens do córrego Restinga, da fazenda Mata Taquaral (Orizona, GO). O clima da região é tropical úmido, caracterizado por duas estações bem definidas: a seca (quando a precipitação média fica abaixo de $10 \mathrm{~mm}$ mensais) e a úmida (com média mensal acima de $250 \mathrm{~mm}$ e temperatura média de $22^{\circ} \mathrm{C}$ ). A latitude é de $17^{\circ} 1^{\prime} 51^{\prime}$ 'S, a longitude de $48^{\circ} 17^{\prime} 45^{\prime \prime} \mathrm{W}$ e a altitude de $1.000 \mathrm{~m}$ acima do nível do mar (Moura 2008).

$\mathrm{O}$ experimento foi realizado em delineamento inteiramente casualizado. Os rizomas colhidos (aproximadamente $30 \mathrm{~kg}$ ) foram selecionados de acordo com a cor (amarelada), visto que não foi possível identificar a idade das plantas adultas. Após a colheita, os rizomas foram lavados em água corrente, arejados e transportados em sacos de polietileno, para minimizar perdas de umidade.

A película que envolve os rizomas foi retirada com facas de aço inoxidável e as amostras colocadas em sacos plásticos, para armazenamento em refrigerador $\left(<10^{\circ} \mathrm{C}\right)$, até o momento das análises. A análise da composição química, incluindo umidade, cinzas, proteínas, matéria graxa, fibras, açúcares solúveis redutores, açúcares totais e amido, foi realizada em triplicatas, segundo metodologia proposta pelo Instituto Adolfo Lutz (1985).

Para a obtenção do amido, seguiu-se o esquema descrito por Leonel et al. (2002a), com modificações. Os rizomas descascados foram picados e acondicionados em recipientes plásticos, contendo metabissulfito de sódio $\left(5 \mathrm{~g} \mathrm{~L}^{-1}\right)$, em proporção de $1 \mathrm{~kg}$ de rizoma por $2 \mathrm{~L}$ de solução de metabissulfito $(1: 2, p / v)$. A moagem foi realizada em moinho de facas, tipo "Croton", modelo MA580 (MARCONI, Piracicaba, Brasil), com peneira de malha de 10 mesh, obtendo-se uma massa, que foi passada em peneiras de 100 mesh e 325 mesh e lavada, sucessivamente, com água corrente, para separação do amido, por decantação, em recipientes plásticos. $\mathrm{O}$ amido decantado foi purificado com álcool absoluto, filtrado a vácuo e desidratado a $45^{\circ} \mathrm{C}$, por 12 horas. $\mathrm{O}$ amido desidratado permaneceu 12 horas em dessecador contendo sílica-gel e, em seguida, foi reduzido a pó, utilizando-se gral e pistilo, e peneirado em peneira de 48 mesh, obtendo-se, assim, a amostra seca para análise.

$\mathrm{O}$ amido foi caracterizado quanto ao $\mathrm{pH}$, acidez titulável e teores de umidade, cinzas, fibras, matéria graxa, proteínas, açúcares totais (Instituto Adolfo Lutz 1985) e amilose (Williams et al. 1970). Estas análises foram feitas em triplicata.

Os grânulos do amido isolado foram avaliados quanto à forma e tamanho, por análise de imagem, utilizando-se a técnica descrita por Vigneau et al. (2000), com modificações. Amostras de amido foram 
coletadas com fio de platina, misturadas sobre lâmina de vidro com uma gota de lugol e, posteriormente, cobertas com lamínula. As lâminas foram observadas em microscópio óptico Leica (DME, Wetzlar, Alemanha) e as imagens selecionadas foram analisadas pelo software LAS EZ. Os parâmetros avaliados foram forma, diâmetro maior e diâmetro menor $(\mu \mathrm{m})$. Foram feitas 10 lâminas e 100 medidas de tamanho de grânulos de amido por lâmina, totalizando mil determinações.

A análise da distribuição do tamanho das partículas do amido foi realizada em duplicata, na unidade de dispersão líquida do equipamento Laser Particle Sizer Analysette 22 (Fritsch, Idar-Oberstein, Alemanha), o qual utiliza o princípio da difração a laser, produzindo laser hélio-neon, no comprimento de onda de $632 \mathrm{~nm}$. As frações granulométricas foram adicionadas lentamente, utilizando-se água deionizada como agente dispersor, sob agitação constante, até que $8 \%$ de obscuridade do feixe de laser fossem alcançados para início da leitura (Ascheri et al. 2006a).

Para a análise da viscosidade, em triplicata, seguiu-se a metodologia de Ascheri et al. (2006b). Foi utilizado o equipamento RVA (Rapid Visco Analyzer 4, Newport Scientific PTY LTD, Sydney, Austrália) (Newport Scientific 1998) e suspensões de amido (2,5 g de amido em $25 \mathrm{~mL}$ de água), corrigidas para a base de $14 \%$ de umidade. As propriedades de pasta foram avaliadas de acordo com a seguinte programação: $50^{\circ} \mathrm{C}$, por 1 minuto; aquecimento de $50^{\circ} \mathrm{C}$ a $95^{\circ} \mathrm{C}$, a uma taxa de $6^{\circ} \mathrm{C} / \mathrm{min}$.; manutenção da pasta a $95^{\circ} \mathrm{C}$, por 5 minutos; e resfriamento de $95^{\circ} \mathrm{C}$ a $50^{\circ} \mathrm{C}$, a uma taxa de $6^{\circ} \mathrm{C} / \mathrm{min}$. A viscosidade foi expressa em rapid visco units (RVU). Do gráfico obtido, foram avaliados os seguintes parâmetros: temperatura de pasta, viscosidade máxima (pico), quebra de viscosidade (diferença entre a viscosidade máxima e a da pasta, mantida a $95^{\circ} \mathrm{C}$, por 5 minutos), viscosidade final e tendência à retrogradação (diferença entre a viscosidade final e da pasta, a $95^{\circ} \mathrm{C}$, por 5 minutos).

O poder de inchamento e a solubilidade dos amidos foram determinados de acordo com método descrito por Peroni (2003).

A análise calorimétrica, em triplicata, foi realizada em calorímetro diferencial de varredura DSC, modelo Q200 (TA Instruments, New Castle, EUA). O instrumento foi calibrado utilizando-se o indium, como padrão. Para determinação da entalpia de gelatinização do amido, foram colocados, aproximadamente, $5 \mathrm{mg}$ da amostra de teor de umidade conhecido em cadinho de alumínio, o qual foi hermeticamente selado. O perfil de varredura utilizado foi equilíbrio a $5^{\circ} \mathrm{C}$, com aquecimento até $110^{\circ} \mathrm{C}$, utilizando-se a taxa de aquecimento de $10^{\circ} \mathrm{C} / \mathrm{min}$., sob fluxo de $50 \mathrm{~mL}$ de nitrogênio/min. A entalpia de gelatinização foi calculada com a ajuda do software Universal Analysis, versão 4.3A.

A análise cristalográfica, em triplicata, foi feita com as amostras fixadas em suporte de alumínio e analisadas à temperatura ambiente, utilizando-se um difratômetro de raios X Rigaku (modelo RU 200 R, Osaka, Japão), operando com filtro monocromático, radiação Ka de cobre, potência de $0,8 \mathrm{~kW}$, corrente de $50 \mathrm{~mA}$ e voltagem de $40 \mathrm{kV}$. O comprimento de onda utilizado foi de $1,54 \AA$. As análises foram feitas entre $2 \theta=5^{\circ}$ e $2 \theta=40^{\circ}$, sendo a velocidade de varredura de $2^{\circ}(2 \theta) / \mathrm{min}$. A intensidade (I) foi expressa em contagem de picos por segundo. O espaço interplanar $\mathrm{d}$ foi calculado fazendo-se uso da equação de Bragg: $I=2 . d \cdot \operatorname{sen} \theta$, onde $\theta$ é a metade do valor do ângulo

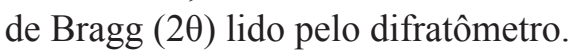

Os dados experimentais foram descritos por meio de médias e desvios-padrões, sendo processados e analisados com o auxílio do programa de análise estatística Statistica 8.0 (Statsoft 2007).

\section{RESULTADOS E DISCUSSÃO}

Os rizomas do lírio-do-brejo (Figura 1) apresentam forma alongada e contorcida, de comprimento e diâmetro diferentes. Na superfície, observa-se uma

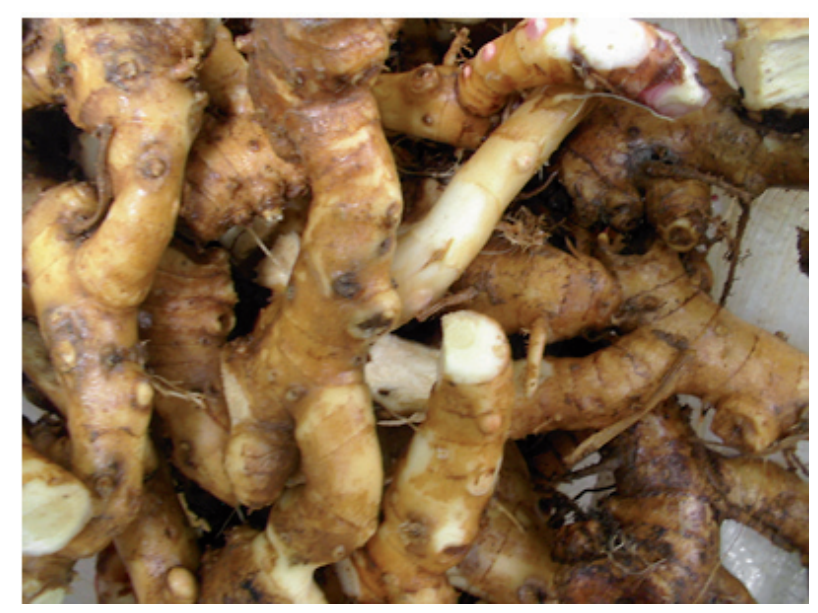

Figura 1. Rizomas do lírio-do-brejo (Hedychium coronarium) coletados no município de Orizona, GO. 
película fina de cor amarelada, quando fisiologicamente desenvolvidos (maduros), ou de cor rósea, quando não alcançam o estado de maturação. A polpa é clara e se oxida em contato com o ar. Por possuir fibras longas, a moagem dos rizomas é dificultada. Além disso, apresentam uma película que possui um látex, que bloqueia os furos das peneiras, dificultando a passagem do amido.

Os rizomas do lírio-do-brejo são constituídos de $82,7 \%$ de umidade. Em base seca, contêm 7,5\% de matéria graxa; $6,94 \%$ de cinza; $5,78 \%$ de proteínas; $7,51 \%$ de fibra bruta; $8,67 \%$ de açúcares solúveis redutores; $28,32 \%$ de açúcares totais; e $21,97 \%$ de amido. Comparando-se estes constituintes químicos com os de rizomas de biri (Canna edulis) (Leonel et al. 2002a) e de ararura (Maranta arundinacea) (Leonel et al. 2002b), que possuíam $76 \%$ e $68 \%$ de umidade (base úmida) e $74 \%$ e $76 \%$ de amido (base seca), respectivamente, os rizomas do lírio-do-brejo apresentam baixos teores de matéria seca $(17,3 \%)$ e de amido, resultados não promissores, considerandose o objetivo de processamento deste rizoma para extração de amido.

Na Tabela 1, pode-se observar que a purificação do amido foi bem sucedida, uma vez que os grânulos possuem baixos teores de outras frações em sua composição química. Este amido apresenta teor de amilose de $37,2 \%$ (base seca) e $62,02 \%$ de amilopectina. Este teor de amilose é maior que os de mandioca (Hoover 2001), arroz (Verwimp et al. 2004) e milho comum (Weber et al. 2009), que foram de $18,6 \%$ a $28,6 \% ; 29,7 \%$; e $27,8 \%$, respectivamente, indicando que o amido do lírio-do-brejo necessita de maior energia para sua gelatinização e que a pasta formada possui menor viscosidade máxima e maior tendência à retrogradação do que as pastas formadas

Tabela 1. Composição química (em base seca) do amido do rizoma do lírio-do-brejo ${ }^{1}$.

\begin{tabular}{cc}
\hline Componente & $\begin{array}{c}\text { Média } \pm \text { desvio-padrão } \\
(\%)\end{array}$ \\
\hline Cinzas & $0,50 \pm 0,03$ \\
Matéria graxa & $0,01 \pm 0,02$ \\
Fibra & $0,24 \pm 0,03$ \\
Proteínas & $0,03 \pm 0,02$ \\
Amilose & $37,20 \pm 1,95$ \\
Amilopectina $^{2}$ & 62,02 \\
\hline
\end{tabular}

${ }^{1}$ Teor de umidade do amido extraído: $6,95 \pm 0,07 \%$ (base seca); ${ }^{2}$ Calculado por diferença. com amidos de mandioca, batata e milho normal. Weber et al. (2009) observaram este comportamento em amidos de milho comum, ceroso e com alto teor de amilose e concluíram que a diminuição da viscosidade máxima, o aumento da tendência à retrogradação e a maior energia gasta para a formação de gel são mais evidenciados para amidos que possuem maior teor de amilose.

Os grânulos de amido extraídos podem ser visualizados na Figura 2. Os grânulos apresentaram forma elipsóide, truncada, pentagonal e irregular, diferente da forma dos grânulos de gengibre (Leonel \& Cereda 2002), porém semelhante à dos grânulos de amido do açafrão (Moorthy 2002), sendo ambas as espécies da mesma família do lírio-do-brejo.

De acordo com Vieira (2004), o tamanho dos grânulos e sua distribuição estão entre os fatores que influenciam as propriedades funcionais dos amidos. Além disso, é um importante parâmetro para se definir etapas do processo de extração deste polissacarídeo. Os grânulos de amido dos rizomas do líriodo-brejo apresentaram distribuição do tamanho das partículas variando de $0,2 \mu \mathrm{m}$ a $70,4 \mu \mathrm{m}$, alcançando uma média de 38,2 $\mu \mathrm{m}$ (Figura 3).

Foi constatada grande irregularidade nos formatos dos grânulos de amido desse rizoma e, por isso, foram mensurados seus diâmetros mínimos e máximos. Os tamanhos médios dos grânulos de amido foram $21,77 \pm 9,97 \mu \mathrm{m}$ (diâmetro mínimo) e 49,52 $\pm 3,21 \mu \mathrm{m}$ (diâmetro máximo).

O perfil de RVA do amido do lírio-do-brejo (Figura 4) mostrou modificações na viscosidade dos grânulos, em função do tempo e da temperatura. Nos

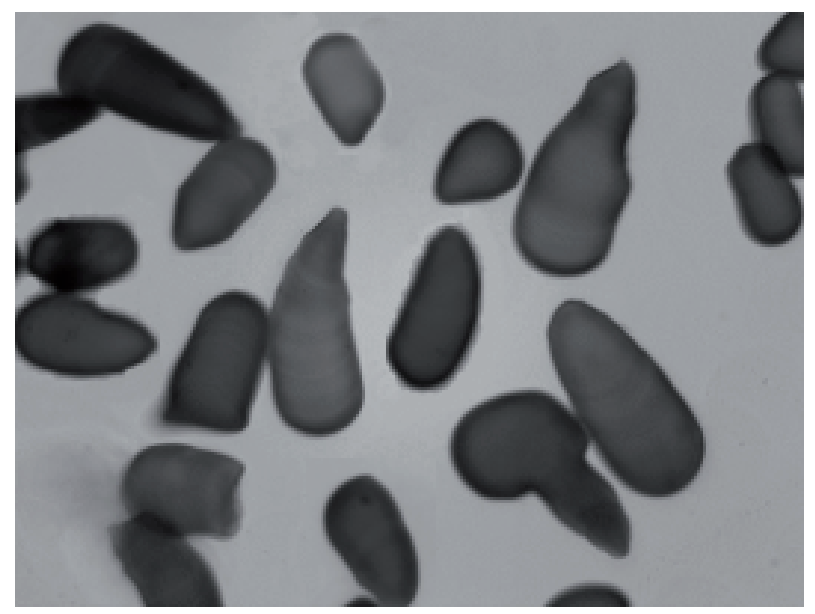

Figura 2. Microfotografia de grânulos de amido isolado de rizomas do lírio-do-brejo (Hedychium coronarium). 


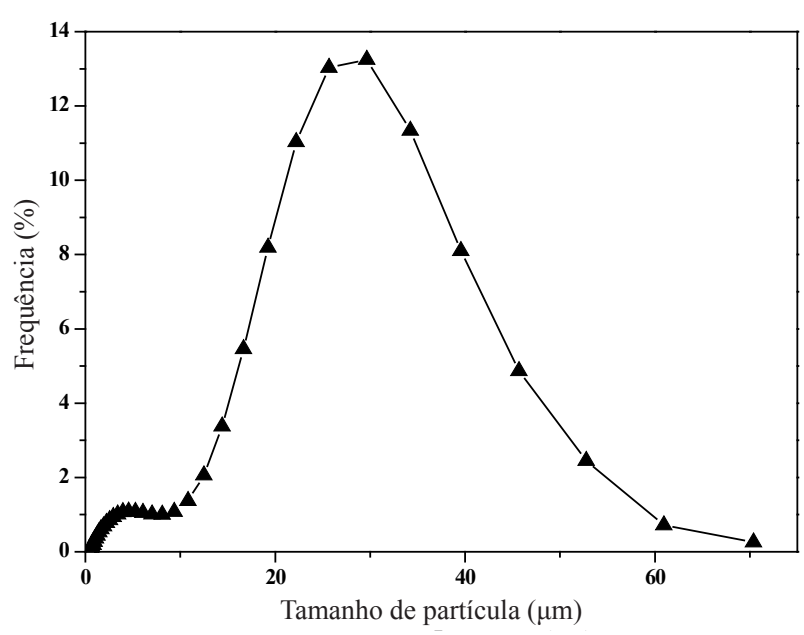

Figura 3. Distribuição do tamanho de partículas do amido isolado dos rizomas do lírio-do-brejo (Hedychium coronarium).

primeiros 4,8 minutos (tempo de pasta), os grânulos de amido não sofreram modificação e a viscosidade mostrou-se muito baixa (0,5 RVU). A temperatura de pasta $\left(78,7^{\circ} \mathrm{C}\right)$ indicou que este amido teve alta resistência à expansão e ruptura (Singh et al. 2004). Após o início da formação de pasta, os grânulos começaram a intumescer, aumentando a viscosidade até $328 \mathrm{RVU}$ (viscosidade de pico no ciclo de aquecimento), em 6,3 minutos, a $95^{\circ} \mathrm{C}$. Durante o período de aquecimento, o perfil de viscosidade apresentou formato arredondado, indicando, ainda, certa resistência das forças de ligação no interior dos grânulos, que, uma vez rompidas, sob agitação contínua, provocam queda de 25 RVU na viscosidade (quebra), em 7,9 minutos. Durante o período de resfriamento, o aumento da viscosidade foi de 245 RVU (tendência à retrogradação).

O amido do lírio-do-brejo possui viscosidade máxima inferior à da mandioca (Daramola \& Osanyinlusi 2006), batata (Leonel et al. 2002a) e milho (Sandhu \& Singh 2007), que foram, aproximadamente, 392 RVU, 754 RVU e 340 RVU, respectivamente. Porém, a tendência à retrogradação foi superior, apresentando valores próximos de $67 \mathrm{RVU}$, 48 RVU e 154 RVU, respectivamente. Estas comparações reforçam as observações feitas por Weber et al. (2009), de que amido contendo elevado teor de amilose possui baixa viscosidade máxima e elevada tendência à retrogradação.

Os valores de poder de inchamento e índice de solubilidade do amido do lírio-do-brejo, obtidos

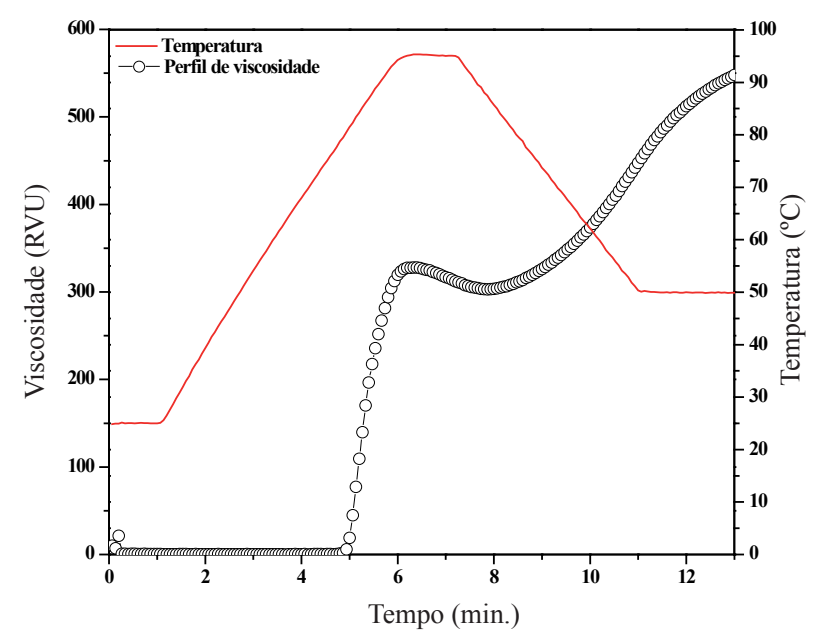

Figura 4. Perfil de viscosidade de pasta do amido isolado dos rizomas de lírio-do-brejo (Hedychium coronarium).

às temperaturas de $30^{\circ} \mathrm{C}$ a $90^{\circ} \mathrm{C}$, são apresentados na Figura 5. Nesta figura, observa-se inclinação mais acentuada da curva do poder de inchamento a partir de $70^{\circ} \mathrm{C}$, sugerindo o início da formação de pasta. Estes resultados estão de acordo com Silva \& Silva (2005) e Peroni et al. (2006), que observaram o mesmo perfil em amido de banana-nanica e amidos de tubérculos de diferentes fontes vegetais, respectivamente, avaliados nas mesmas condições do presente estudo. Com base no formato da curva do poder de inchamento do amido do lírio-do-brejo, pode-se dizer que os grânulos são resistentes e menos susceptíveis à ruptura, com o aquecimento prolongado, em razão

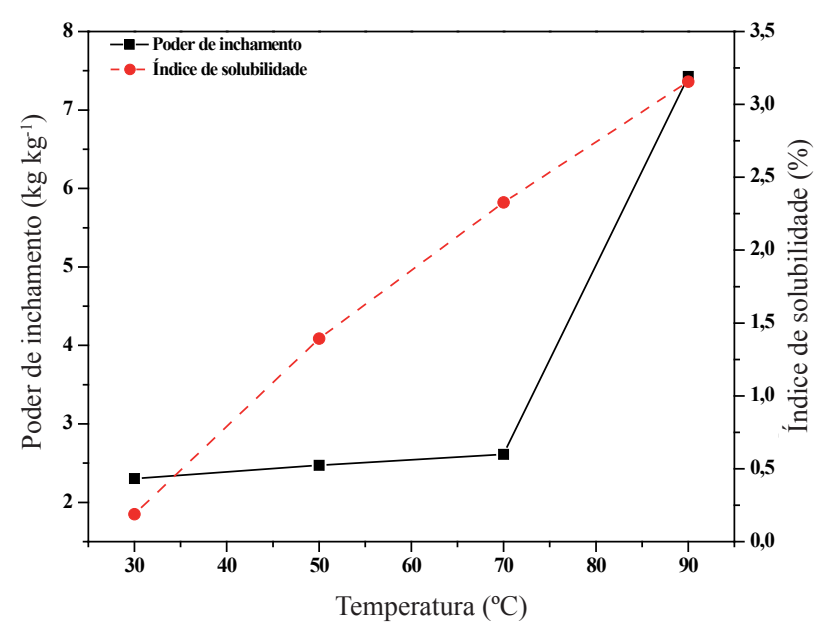

Figura 5. Poder de inchamento e índice de solubilidade de amido isolado dos rizomas do lírio-do-brejo, nas temperaturas de $30^{\circ} \mathrm{C}$ a $90^{\circ} \mathrm{C}$. 
da baixa tendência ao inchamento. Estas forças são inferiores às encontradas por Yuan et al. (2007), para amidos de mandioca e batata, a $90^{\circ} \mathrm{C}$, cujo poder de inchamento foram de $55 \mathrm{~kg} \mathrm{~kg}^{-1}$ e $87 \mathrm{~kg} \mathrm{~kg}^{-1}$, respectivamente. Portanto, o amido isolado dos rizomas do lírio-do-brejo gelatiniza-se mais lentamente e incha menos, quando comparado com os de mandioca e batata.

O teor de amilose presente no amido do líriodo-brejo deve ter contribuído para a restrição do seu inchamento, em função de suas moléculas lineares fortemente ligadas, uma vez que a proporção de amilose e amilopectina podem interferir no grau de associação, composição e distribuição das zonas cristalinas do amido (Hoover 2001).

$\mathrm{O}$ índice de solubilidade aumentou com o aumento da temperatura e o valor constatado, no presente estudo, é inferior ao dos amidos de mandioca e batata, em todas as temperaturas aplicadas (Yuan et al. 2007). A solubilidade dos amidos se deve, em grande parte, à solubilização da amilose, que é lixiviada do grânulo, durante a gelificação, ou mesmo pelo amido danificado, durante o processo de extração (Peroni 2003).

De acordo com Krieger et al. (1997), as propriedades térmicas, durante o processo de gelatinização do amido, são muito importantes para a determinação de sua funcionalidade e utilização na indústria. As propriedades térmicas do amido do lírio-do-brejo estão apresentadas na Tabela 2. Comparando-se as temperaturas iniciais de gelatinização (To), obtidas do DSC, com as temperaturas de pasta do RVA, observa-se que a temperatura inicial de formação de pasta do amido do lírio-do-brejo apresentou valor menor, em relação à temperatura de pasta $\left(78,7^{\circ} \mathrm{C}\right)$. A mesma observação foi feita por Peroni (2003), para amidos de mandioca e outras espécies vegetais, que apresentam temperaturas de pasta maiores do que as obtidas pelo DSC. De acordo com Pérez et al. (1998), a temperatura de pasta obtida pelo RVA apresenta-se mais elevada, devido à menor sensibilidade em detectar os

Tabela 2. Propriedades de gelatinização de amido isolado dos rizomas do lírio-do-brejo.

\begin{tabular}{cccc}
$\mathrm{To}^{1}\left({ }^{\circ} \mathrm{C}\right)$ & $\mathrm{Tp}^{2}\left({ }^{\circ} \mathrm{C}\right)$ & $\mathrm{Tc}^{3}\left({ }^{\circ} \mathrm{C}\right)$ & $\Delta \mathrm{H}^{4}\left(\mathrm{~kJ} \mathrm{~kg}^{-1}\right)$ \\
\hline $73,10 \pm 0,27$ & $79,22 \pm 0,06$ & $99,90 \pm 0,28$ & $16,16 \pm 0,72$
\end{tabular}

Temperatura inicial; ${ }^{2}$ Temperatura de pico; ${ }^{3}$ Temperatura de conclusão; ${ }^{4}$ Variação de entalpia. primeiros acréscimos na viscosidade de pasta dos amidos, diferentemente da temperatura inicial de gelatinização, que é detectada quando os primeiros grânulos começam a se desorganizar. Os valores do DSC são mais precisos, enquanto os do RVA apresentam uma faixa de temperatura. Segundo Yoo \& Jane (2002), uma única endoterma no gráfico apresentado pelo DSC dos amidos significa que não há amilose complexada com lipídios, já que esta, se existente, poderia se fundir, proporcionando uma endoterma na faixa de temperatura de $91-100^{\circ} \mathrm{C}$. Isto era de se esperar, uma vez que amidos de raízes e tubérculos apresentam quantidades muito baixas de lipídios. Como citado anteriormente, a presença de matéria graxa no amido do lírio-do-brejo foi baixa (Tabela 1). O valor desta endoterma foi de $16,16 \mathrm{~kJ} \mathrm{~kg}^{-1}$, superando as endotermas do amido de mandioca $\left(13,73 \mathrm{~kJ} \mathrm{~kg}^{-1}\right)$ (Peroni 2003), por possuir maior teor de amilose.

Considerando-se que os grânulos de amido são parcialmente cristalinos, foram estabelecidos padrões específicos (A, B e C) de difração de raios $\mathrm{X}$, variáveis com a fonte botânica. Os padrões de cristalinidade são definidos com base nos espaços interplanares (d) e na intensidade relativa das linhas de difração dos raios X. Segundo Zobel (1988), o padrão $\mathrm{A}$ apresenta picos fortes nos espaços inter-

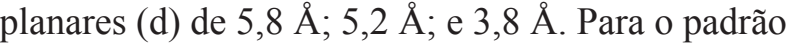
$\mathrm{B}$, este autor destaca que um pico forte está entre $15,8 \AA$ e $16,0 \AA$, um pico com menor intensidade e mais largo a 5,9 $\AA$ e outro a 5,2 $\AA$ e um par de picos com intensidade de média a forte em 4,0-3,7 Å. Já o padrão $\mathrm{C}$ é semelhante ao padrão $\mathrm{A}$ e apresenta um pico a mais em $16 \AA$. O difratograma de raios X dos grânulos de amido do lírio-do-brejo pode ser observado na Figura 6. Na Tabela 3, estão os valores do ângulo $2 \theta$ e respectivos valores de espaço interplanar e intensidade do amido do lírio-do-brejo. O amido

Tabela 3. Principais picos de intensidade de difração de raios $\mathrm{X}$ de amido isolado dos rizomas do lírio-do-brejo.

\begin{tabular}{ccc}
\hline Ângulo $2 \theta$ & Intensidade & $\mathrm{d}(\AA)^{1}$ \\
\hline 14,70 & $1.061,73$ & 6,02 \\
17,47 & $1.609,41$ & 5,07 \\
19,63 & $1.336,86$ & 4,52 \\
22,72 & $1.479,18$ & 3,91 \\
24,17 & $1.400,69$ & 3,68 \\
26,78 & $1.279,08$ & 3,33 \\
\hline
\end{tabular}

${ }^{1}$ Espaços interplanares, calculados de acordo com a equação de Bragg (Zobel 1988). 


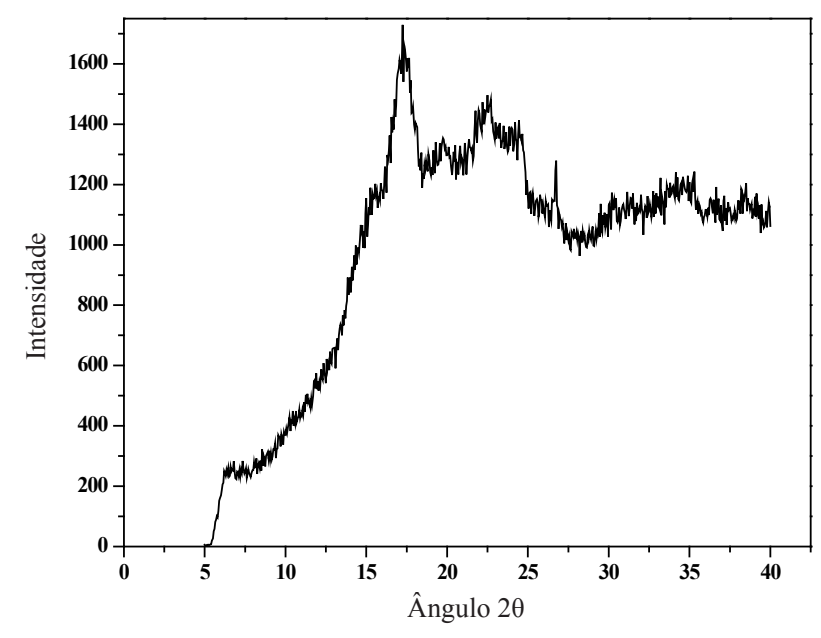

Figura 6. Difratograma de raios $\mathrm{X}$ de amido isolado dos rizomas de lírio-do-brejo.

do lírio-do-brejo apresentou seis picos principais, em torno dos ângulos de difração, de $14,7^{\circ} ; 17,5^{\circ} ; 19,6^{\circ}$; $22,7^{\circ} ; 24,2^{\circ} ;$ e $26,8^{\circ}$, picos, estes, característicos dos grânulos de estrutura tipo A.

\section{CONCLUSÕES}

1. O rizoma do lírio-do-brejo apresenta baixos teores de matéria seca e de amido e contém fibras longas e látex, que dificultam o processo de extração do amido. Por causa destas características, os rizomas do lírio-do-brejo não são adequados para uso como matéria-prima amilácea.

2. O amido do lírio-do-brejo possui estrutura cristalina do tipo A, com teor de amilose superior aos teores médios dos amidos de mandioca, batata e milho. Seus grânulos apresentam tamanhos variados (em torno de 38,2 $\mu \mathrm{m}$ ), elevada temperatura de empastamento e baixa tendência ao inchamento. Também, pouco se solubilizam e suas pastas apresentam elevada estabilidade frente ao calor, sob agitação mecânica, e alta tendência à retrogradação.

\section{AGRADECIMENTOS}

À Universidade Estadual de Goiás e à Embrapa Agroindústria de Alimentos, pelo apoio na realização das análises. À Coordenação de Aperfeiçoamento de Pessoal de Nível Superior (Capes) e à Fundação de Amparo à Pesquisa do Estado de Goiás (Fapeg), pelo suporte financeiro.

\section{REFERENNCIAS}

AGAREZ, F. V.; PEREIRA, C.; ATÍDIO, C. Botânica: taxonomia, morfologia e reprodução dos Angiospermae: chaves para determinação das famílias. 2. ed. Rio de Janeiro: Âmbito Cultural, 1994.

ASCHERI, D. P. R. et al. Efeito da extrusão sobre a adsorção de água de farinhas mistas pré-gelatinizadas de arroz e bagaço de jabuticaba. Ciência e Tecnologia de Alimentos, Campinas, v. 26, n. 2, p. 325-335, 2006 a.

ASCHERI, D. P. R. et al. Obtenção de farinhas mistas pré-gelatinizadas a partir de arroz e bagaço de jabuticaba: efeito das variáveis de extrusão nas propriedades de pasta. Boletim do Centro de Pesquisa de Processamento de Alimentos, Curitiba, v. 24, n. 1, p. 115-144, 2006b.

BOBBIO, P. A.; BOBBIO, F. O. Química do processamento de alimentos. 3. ed. rev. São Paulo: Varela, 2003.

DARAMOLA, B.; OSANYINLUSI, S. A. Investigation on modification of cassava starch using active components of ginger roots (Zingiber officinale Roscoe). African Journal of Biotechnology, Nairobi, v. 5, n. 10, p. 917-920, 2006.

HERNÁNDEZ-MEDINA, M. et al. Caracterización fisicoquímica de almidones de tubérculos cultivados en Yucatán, México. Ciência e Tecnologia de Alimentos, Campinas, v. 28, n. 3, p. 718-726, 2008.

HOOVER, R. Composition, molecular structure, and physicochemical properties of tuber and root starches: a review. Carbohydrate Polymers, Oxford, v. 45, n. 3, p. 253-267, 2001.

INSTITUTO ADOLFO LUTZ. Normas analíticas: métodos químicos e físicos para análises de alimentos. 3. ed. São Paulo: Instituto Adolfo Lutz, 1985.

KRIEGER, K. M. et al. Thermal properties of corn starches extracted with different blending methods: micro blender and homogeneizer. Cereal Chemistry, Saint Paul, v. 74, n. 5, p. 553-555, 1997.

LEONEL, M.; CEREDA, M. P. Caracterização físicoquímica de algumas tuberosas amiláceas. Ciência e Tecnologia de Alimentos, Campinas, v. 22, n. 1, p. 65-69, 2002.

LEONEL, M. et al. Extração e caracterização de amido de biri (Canna edulis). Brazilian Journal of Food Technology, Campinas, v. 5, n. 1, p. 27-32, 2002a.

LEONEL, M.; CEREDA, M. P.; SARMENTO, S. B. S. Processamento de araruta (Maranta arundinacea) para extração e caracterização da fração amilácea. Brazilian Journal of Food Technology, Campinas, v. 5, n. 93, p. 151$155,2002 b$. 
MOORTHY, S. N. Physicochemical and functional properties of tropical tuber starches: a review. Starch/ Stärke, Weinheim, v. 54, n. 12, p. 559-592, 2002.

MOURA, W. de S. Extração e caracterização do amido do Hedychium coronarium e elaboração de filmes biodegradáveis. 2008. 82 f. Dissertação (Mestrado em Ciências Moleculares)-Universidade Estadual de Goiás, Anápolis, 2008.

NEWPORT SCIENTIFIC. Applications manual for the Rapid Visco Analyser. Warriewood: Instrument Support Group, 1998.

PÉREZ, E. E.; BREENE, W. M.; BAHNASSEY, Y. A. Variations in the gelatinization profiles of cassava, sagu and arrowroot native starches as measured with different thermal and mechanical methods. Starch/Stärke, Weinheim, v. 50, n. 2-3, p. 70-72, 1998.

PERONI, F. H. G. Características estruturais físicoquímicas de amidos obtidos de diferentes espécies tropicais. 2003. 118 f. Dissertação (Mestrado em Engenharia e Ciência de Alimentos)-Universidade Estadual Paulista Júlio de Mesquita Filho, São José do Rio Preto, 2003.

PERONI, F. H. G.; ROCHA, T. S.; FRANCO, C. M. L. Some structural and physicochemical characteristics of tuber and root starches. Food Science and Technology International, New York, v. 12, n. 6, p. 505-513, 2006.

SANDHU, K. S.; SINGH, N. Some properties of corn starches II: physicochemical, gelatinization, retrogradation, pasting and gel textural properties. Food Chemistry, Oxford, v. 101, n. 4, p. 1499-1507, 2007.

SILVA, M. H. L; SILVA, C. O. Caracterização parcial de amido de banana-nanica (Musa sp. AAA Cavendich). Revista Ceres, Viçosa, v. 52, n. 303, p. 751-762, 2005.

SINGH, N. et al. Physicochemical, thermal, morphological and pasting properties of starches from some Indian black gram (Phaseolus mungo L.) cultivars. Starch/Stärke, Weinheim, v. 56, n. 11, p. 535-544, 2004.

STATSOFT. Statistica (data analysis software system). Version 8.0. Tulsa: StatSoft, 2007. 1 CD-ROM.

VERWIMP, T. et al. Isolation and characterization of rye starch. Journal of Cereal Science, London, v. 39, n. 11, p. 85-90, 2004.
VIEIRA, F. C. Efeito do tratamento com calor e baixa umidade sobre características físicas e funcionais dos amidos de mandioquinha-salsa (Arracacia xanthorrhiza), de batata-doce (Ipomoea batatas) e de gengibre (Zingiber officinale). 2004. 122 f. Dissertação (Mestrado em Ciência e Tecnologia de Alimentos)-Escola Superior de Agricultura “Luiz de Queiroz", Universidade de São Paulo, Piracicaba, 2004.

VIGNEAU, E. et al. Number of particles for the determination of size distribution from microscopic images. Powder Technology, Amsterdam, v. 107, n. 3, p. 243-250, 2000.

WANG, L. Z.; WHITE, P. J. Functional properties of oats starches and relationships among functional and structural characteristics. Cereal Chemistry, St. Paul, v. 71, n. 5, p. 451-458, 1994a.

WANG, L. Z.; WHITE, P. J. Structure and physicochemical properties of starches from oats with different lipid contents. Cereal Chemistry, St. Paul, v. 71, n. 5, p. 443450, $1994 b$.

WEBER, F. H.; COLLARES-QUEIROZ, F. P.; CHANG, Y. K. Caracterização físico-química, reológica, morfológica e térmica dos amidos de milho normal, ceroso e com alto teor de amilose. Ciência e Tecnologia de Alimentos, Campinas, v. 29, n. 4, p. 748-753, 2009.

WILLIAMS, P. C.; KUZINA, F. D.; HLYNKA, I. A rapid colorimetric method for estimating the amylose content of starches and flours. Cereal Chemistry, St. Paul, v. 47, n. 4, p. 411-421, 1970 .

YOO, S. H.; JANE, J. I. Structural and physical characteristics of waxy and other wheat starches. Carbohydrate Polymers, Oxford, v. 49, n. 3, p. 297-305, 2002.

YUAN, Y. et al. Physicochemical properties of starch obtained from Dioscorea nipponica Makino comparison with other tuber starches. Journal of Food Engineering, Oxford, v. 82, n. 4, p. 436-442, 2007.

ZOBEL, H. F. Starch crystal transformations and their industrial importance. Starch/Stärke, Weinheim, v. 40, n. 1, p. 1-7. 1988 . 